\title{
Where has the new information gone? The Chinese case ${ }^{*}$
}

\author{
Marie-Claude Paris \\ Université Denis Diderot-Paris 7 \\ marie-claude.paris@ linguist.jussieu.fr
}

\section{Introduction}

In this paper I would like to show that the principles which have been proposed so far to account for the relationship between the informational level and the syntactic level in a Chinese utterance are unable to predict some interesting and regular facts of that language.

To my mind, the form and the position of the question operator in an interrogative utterance provide two distributional tests which univocally indicate where the new information lies. Hence, the pairing of affirmative and interrogative sentences might be a better approach to locate where the new information lies in a Chinese utterance.

\section{Previous analyses}

Functional as well as formal analyses have offered principles which try to relate the scope of operators, such as negation or question - hence the domain of new information - to the (surface) syntactic level.

\subsection{The functional paradigm}

Functional linguists have associated one of the general typological characteristics of Chinese, i.e. topic prominence, with iconic properties of word order. In such a perspective, the direction of word order, that is from left to right, is directly correlated with the position of old and new information. Old information stands in preverbal position, whereas new information stands in postverbal position (see Tai (1989), Tsao (1990), among others). Consequently, there is scope transparency and the absence of what is called 'negative transportation' in English is predicted for Chinese.

In English, it is well known that the negative marker modifies the matrix verb in (01), but that its scope may be on the subordinate verb, so that $(01)$ can be paraphrased as $(02)$.

(01) I don't think he will be here today

(02) I think he won't be here today

If negative transportation does not exist in Chinese, we can immediately predict the difference in grammaticality between (03) and (04). (03), which is built on the same pattern as $(01)$ is ill-formed.

\footnotetext{
Thanks to W. Paul and H-D. Gasde for their comments on a preliminary version of this paper. I alone take responsibility for the possible remaining errors.

The abbreviations used here are:

Cl. : Classifier, F.P. : Final Particle; Inter. : Interrogation; Neg.: Negation; Suf.: Suffix.
} 
(03)

*wo bu xiang ta jintian hui lai le I Neg. think he today can come F.P.

I don't think he will come today
wo xiang ta jintian bu hui lai le
I think he today Neg. can come F.P.
I don't think he will come today

Such a phenomenon is attested in complement clauses as well as in adverbial clauses. Thus the ambiguity found in the English example (05) does not arise.

(05) I did not go because I was scared

(05a) I did not go, because I was scared

(05b) I went, (but) not because I was scared

(06) below corresponds to interpretation (05a), while (07) corresponds to (05b).

$$
\text { wo mei qu, yinwei wo haipa }
$$

I Neg. go because I afraid

I did not go, because I was scared

$$
\begin{aligned}
& \text { wo qu-le, (dan bing) bu shi yinwei haipa } \\
& \text { I go-Suf. (but and) Neg. be because afraid } \\
& \text { I went, (but it was) not because I was afraid }
\end{aligned}
$$

\subsection{The formal paradigm}

\subsubsection{Simple sentences}

Contrary to functional linguists, formal linguists posit an abstract level, called LF (Logical Form), where meaning is computed. In that vein of research, Ernst (1994:245) - among others $^{1}$ - posits the isomorphic principle (IsoP), which accounts for the un-grammaticality of (08) as opposed to the grammaticality of $(09)^{2}$. This principle reads as follows: "If an operator A has scope over B at SS, then A has scope over B at LF".

$$
\begin{aligned}
& \text { *ta yiding qu bu qu? } \\
& \text { he definitely go-Neg.-go }
\end{aligned}
$$

ta shi bu shi yiding qu?

he be-Neg.-be definitely go

is he definitely going?

The ungrammaticality of (08) "can be accounted for by assuming that the A-Not-A form [+Qu] raises to Comp at $\mathrm{LF}$ and that any adjunct which c-commands [+Qu] at SS must also raise to ccommand it at LF...If the adverb is incompatible with scope over [+Qu] , as most core adjuncts are, the result will be ruled out." (ibid.: 260). As the reader can see, first, if the ungrammaticality of (08) finds a mechanic description, nothing is said about the fact that the question needs to be marked with shi bu shi 'is it (the case) that ... ?'. Second, how can the difference between (08) and (10) be accounted for, except from stating the following tautology: yiding 'definitely' is

\footnotetext{
See also Huang (1982) or Aoun and $\mathrm{Li}(1989)$.

2 (8) and (9) are numbered (9b) and (12a) in Ernst (1994).
} 
marked as incompatible with question marking on the verb, hence the ungrammaticality of (08), while jiujing 'finally' is marked as compatible, hence the grammaticality of (10)?

$$
\begin{aligned}
& \text { ta jiujing qu bu qu? } \\
& \text { he finally go-Neg.-go } \\
& \text { finally, is he going? }
\end{aligned}
$$

How can the ill-formedness of (08) be related to the well-formedness of (10)? Moreover, although the adjuncts jiujing 'finally' and zhongyu 'finally' share some semantic properties, why do (10) and (11) differ in grammaticality?

$$
\begin{aligned}
& \text { *ta zhongyu lai bu lai? } \\
& \text { he finally come-Neg.-come }
\end{aligned}
$$

\subsubsection{Complex sentences}

As far as complex sentences are concerned and in order to capture the so-called 'topic prominence' of the Chinese language, Gasde and Paul (1996) introduce a functional projection called 'Topic Phrase', which can be occupied by two types of subordinate clauses. Generating adjunct clauses in the specifier position of a Topic Phrase automatically provides them with the surface order subordinate + matrix clause. In their perspective, both conditional and causal clauses, as illustrated in $(12)$ and $(13)^{3}$, occupy to the same position."To generate adjunct clauses in the specifier position of TopP allows us to automatically derive the rigid word order "adjunct clause - main clause" observed in complex sentences with causal and conditional clauses" (ibid.: 285).

$$
\begin{aligned}
& \text { ruguo ni yao mai fangzi (de hua) wo jiu jiegei ni qian } \\
& \text { if you want buy house (if) I jiu lend you money } \\
& \text { if you want to buy a house, I will lend you some money }
\end{aligned}
$$

$$
\begin{aligned}
& \text { yinwei ta pingshi zhuyi duanlian, suoyi shenti yizhi hen hao } \\
& \text { because he usually mind exercise therefore body always very good } \\
& \text { because he does sports regularly, he is in excellent health }
\end{aligned}
$$

\subsection{Problems}

From what I have somewhat sketchily presented above, one could gather the impression that Chinese is somehow more 'regular' or more iconic than English. Chinese would evidence only direct scope ${ }^{4}$ - as in (03)-(04) - while informational properties (topic prominence) would be correlated to surface order properties (adjunct preceding main clause) - as in (12)-(13).

\subsubsection{The existence of inverse scope}

Example (14) shows that, apart from direct scope, inverse scope also exists in Chinese.

$$
\begin{aligned}
& \text { ta jiu neng he yi bei jiu } \\
& \text { he only can drink one } \mathrm{Cl} \text {. alcohol } \\
& \text { he can only drink one glass of wine }
\end{aligned}
$$

(10) corresponds to (20b) and (11) to (21a) in Gasde and Paul's paper.

4 See Huang (1981) for the one-to-one correspondence between word order and the scopal properties of quantifiers. 
If (15) were to follow direct scope assignment, the modal verb neng 'can', which has wider scope than the focus adverb $j i u^{5}$, should precede it. Hence (15) is predicted to be well-formed, but it is not.

$$
\begin{aligned}
& \text { *ta neng jiu he yi bei jiu }{ }^{6} \\
& \text { he can only drink one Cl. alcohol }
\end{aligned}
$$

Hence inverse scope ${ }^{7}$ does exist in Chinese. Using different syntactic patterns and the cooccurrence between different types of quantifiers in subject and in object positions, Lee, Yip and Wang (1999) have demonstrated that inverse scope in Chinese is influenced by the lexical properties of quantifiers ${ }^{8}$ and by the thematic roles played by objects. Thus, for instance, inverse scope is more readily available to goal/location objects, especially when quantified by $m e i$ + Classifier 'every' than they are to theme objects, especially when such objects are quantified by suoyoude 'all'. Thus, (16), where the object suoyoude ge 'all the songs' is a theme, shows no inverse scope effect, while inverse scope is possible for (17). In (17), the object mei ge wuding 'every roof' is locative.

$$
\begin{aligned}
& \text { zai zhei ci yinyuehui-shang, you liang ge gexing chang-le suoyoude ge } \\
& \text { at this } \mathrm{Cl} \text {. concert-on have two Cl. star sing-Suf. all song } \\
& \text { at this concert, two singers sang all the songs } \\
& \text { (liang ge > suoyoude) }
\end{aligned}
$$

zai na tiao jie, you liang ge qiqiu piao-guo-le mei ge wuding at that $\mathrm{Cl}$. street have two $\mathrm{Cl}$. balloon float-Suf.-Suf. each $\mathrm{Cl}$. rooftop on that street two balloons floated to every roof (mei ge > liang ge; liang ge > mei ge)

\subsubsection{The existence of different types of adjunct clauses}

That Gasde and Paul's analysis fails to account for many distributional facts which differentiate conditional clauses from causal ones has been convincingly argued for by Tsai (1995a, 1995b). She uses eight tests (deletion of the subject of the matrix clause, topicalisation, embedding in tensed clauses, relative clause formation, focussing, constituent questioning in the matrix clause, the scope of the shi-bu-shi operator and anaphoric pronominalization in the matrix

5 Note that when it is interpreted as a restrictive/focus adverb as in (12) jiu takes scope on the right on the quantified object. When it indicates a causal/consequential/anaphoric relation it takes scope on the left (see II below). To my knowledge, such a difference together with its ensuing consequences has gone unnoticed in the literature.

6 In an interrogative pattern though, the expected scope is found, as in (i), where neng 'can' precedes jiu.

(i) ta neng bu neng jiu he yi bei jiu?

he can-Neg.-can only boire un $\mathrm{Cl}$. alcohol can he drink only one glass of wine?

(i) corroborates what I say about the basicness of interrogative word order in Chinese in § III.

7 "An expression $a$ has inverse scope over an expression $b$ iff $b$ is in the semantic scope of $a$ but $a$ does not c-command $b$ at S structure", De Swart (1998). See also Buring (1997). (i) below is acceptable because the negation marker has inverse scope on the negative polarity item. Its semantic scope is wider than its syntactic scope. Inverse scope is felicitous if the wide scope interpretation of negation entails a positive statement, or pragmatically carries a positive implicature.

(i) [a doctor who knew anything about acupuncture] was not available

8 In order to account for quantifer scope interpretations, Kuno et al. (1999) propose an expert system which takes into consideration both syntactic and non syntactic principles. One of these principles reads as follows: a syntactically topicalized quantified expression always has wide scope over a syntactically nontopicalized quantified expression". 
clause) to prove that conditional clauses and causal clauses present different informational properties. Conditional clauses carry old information, while causal clauses carry new information. As expected, the affirmative/interrogative pair (18)-(19) attested for conditional complex sentences has no causal counterpart, cf. (20)-(21) ${ }^{9}$. The matrix in (19) contains an interrogative pronoun shei 'who?' which is the locus of new information; the matrix of (21) cannot, because it is presupposed.

$$
\begin{aligned}
& \text { ruguo Zhangsan shengbing, Lisi hui qu mai yao } \\
& \text { if Zhangsan be ill Lisi can go buy medicine } \\
& \text { if Zhangsan falls ill, Lisi will go and buy medicine }
\end{aligned}
$$

ruguo Zhangsan shengbing, shei hui qu mai yao?

if Zhangsan be ill who? can go buy medicine

if Zhangsan falls ill, who will go and buy medicine?

yinwei Zhangsan shengbing, Lisi hui qu mai yao

because Zhangsan be ill Lisi can go buy medicine

because Zhangsan is ill, Lisi will go and buy medicine

*yinwei Zhangsan shengbing, shei hui qu mai yao?

because Zhangsan be ill who? can go buy medicine

In the following, I will study both complex and simple sentences which contain two connectors jiu and cai. I will try to demonstrate that, in Chinese, there is no one-to-one correspondence between three levels of analysis: the informational level (topic), the tagging level (subordinate clause) and the syntactic level (left to right, subordinate before main clause). In other words, the (automatic) association between the terms of the triplet <topic, subordinate clause, and left position $>$ is ill-grounded.

\section{The question operator and informational properties}

\subsection{Complex sentences}

One of the characteristics of complex sentences in Chinese is that both their subordinate and their main clauses contain markers which hold a tight (semantic) relationship. Subordinators are in construction with a connector ${ }^{10}$, which co-vary according to the logical relationship between clauses. Thus, for instance, the connector of hypothetical clauses (jiu) is different from the concessive connectors (keshi, ye). Within conditional clauses ${ }^{11}$, one can draw a (semantic) distinction between sufficient conditionals containing jiu and necessary conditionals containing cai. Even though both types of conditional clauses are treated as generated under the same node by Gasde and Paul (1996:271-272), I would like to show that they behave differently when they are questioned. Briefly, I would like to demonstrate that conditionals which are in the scope of jiu are presupposed, while conditionals which are in the scope of cai are asserted.

9 (17)-(20) correspond to (18a, b) and (19a,b) in Tsai (1995a).

Le Querler (1993) shows that among subordinate clauses appearing in sentence initial position in French, such as car $p$, puisque p, comme p or étant donné que p, only causal clauses parce que $p$ can be clefted. yinwei translates as 'parce que'.

10 For an overview of such a relationship, cf. Paris (1983) and (1984).

11 Causal and temporal clauses, too. 
In (01) below, the interrogation is marked by a sentence final particle ma, whose scope is both wide and unclear. Does $m a$ bear on the subordinate clause only, on the matrix clause only or on the relation ${ }^{12}$ between both clauses?

$$
\begin{aligned}
& \text { ruguo tianqi hen leng, Lisi jiu hui qu mai shu ma? } \\
& \text { if weather very cold Lisi jiu can go buy book Inter. } \\
& \text { is it the case that if it is cold, Lisi will go and buy books? }
\end{aligned}
$$

One way to disambiguate a question marked by $m a$ is to use its verbal counterpart, called the A-not-A question. Its scope is necessarily small: its does not appear in sentence final position. Within one given clause, it shows up at the level of the predicative phrase, on the first verb. The first verb of the subordinate clause of $(01)$ is the stative verb leng 'be cold'. If it is questioned as in (02) below, the sentence is ungrammatical.

*ruguo tianqi leng bu leng, Lisi jiu hui qu mai shu?

if weather cold-Neg.-cold Lisi jiu can go buy book

The ill-formedness of (02) is expected: in general, a conditional clause is presupposed, hence it cannot fall under the scope of negation or question. So, we predict that only the (first) verb of the predicate of the matrix clause of (01) should allow questioning. Thus (03) should be acceptable. But, contrary to expectation, it is not.

$$
\begin{aligned}
& \text { *ruguo tianqi hen leng, Lisi jiu hui bu hui qu mai shu? } \\
& \text { if weather very cold Lisi jiu can-Neg.-can go buy book }
\end{aligned}
$$

Only (04), which is identical to (03), except for the presence of jiu is well-formed. (05) is also acceptable, but it is not identical in meaning with (04). (04) is more frequent than (05).

(04) ruguo tianqi hen leng, Lisi $\emptyset$ hui bu hui qu mai shu? if weather very cold Lisi $\varnothing$ can-Neg.-can go buy book if it is cold, will Lisi go and buy books?

ruguo tianqi hen leng, Lisi hui bu hui jiu qu mai shu? if weather very cold Lisi can-Neg.-can jiu go buy book if it is cold, would Lisi go and buy books?

I will turn to the semantic explanation of the deletion or the unexpected positioning of jiu later on. For the time being, I will compare the questioning of conditionals with jiu (as in (01)) with the questioning of conditionals with cai (as in (06)).

(06) ni zhiyou caiqu zhei ge banfa cai neng xue-hao ma? // you only adopt this $\mathrm{Cl}$. method cai can study-well Inter.

(01) is it the case that only if you adopt this method you will succeed in learning?

In (01), as in (06), the question particle ma appears in sentence final position. Contrary to (04)-(05), the verb in the matrix clause cannot be questioned: (07)-(09) are not acceptable.

(07) *ni zhiyou caiqu zhei ge banfa cai neng bu neng xue-hao? $/ /(03)$ you only adopt this Cl. method cai can-Neg.-can study-well?

12 Gasde and Paul's analysis (ibid.:273) predicts this sole possibility. 
(08) *ni zhiyou caiqu zhei ge banfa $\emptyset$ neng bu neng xue-hao?

// (04) you only adopt this Cl. method $\varnothing$ can-Neg.-can study-well?

(09) *ni zhiyou caiqu zhei ge banfa neng bu neng cai xue-hao?

// (05) you only adopt this Cl. method can-Neg.-can cai study-well?

The predicate of the subordinate clause caiqu 'adopt' is the only one left and available for questioning. But again, such a question is not acceptable.

$$
\begin{aligned}
& \text { *ni zhiyou caiqu bu caiqu zhei ge banfa cai neng xue-hao? } \\
& \text { you only adopt-Neg.-adopt this Cl. method cai can study-well }
\end{aligned}
$$

Only (11) below is acceptable. In its matrix clause, the question operator is marked not by the verb contained in the clause, but by an 'extra' verb, the copula shi 'be'. The presence of $s h i$ is to indicate that there is a presupposition ${ }^{13}$. Notice that contrary to $(04)$ above where the connector $j i u$ was absent, the connector cai is present.

$$
\begin{aligned}
& \text { ni shi bu shi zhiyou caiqu zhei ge banfa cai neng xuehao? } \\
& \text { you be-Neg.-be only adopt this Cl. method cai can study-well } \\
& \text { is it the case that only if you adopt this method you will succeed in } \\
& \text { learning? }
\end{aligned}
$$

To sum up, conditionals marked by jiu and those marked by cai behave differently under questioning. Both the question marker and their positions vary. The (auxiliary) verb in the matrix clause is questioned in (04), while jiu is deleted. The copula is questioned in the subordinate clause of (11), while the connector cai remains present. Hence we can conclude that conditionals containing jiu and those containing cai cannot appear under the same (functional) projection. A jiu conditional is indeed a topic: it cannot be questioned. On the contrary, a cai conditional is not a topic: it does carry new information and falls in the scope of the question operator.

Two other tests prove that conditionals with jiu and thoese with cai play different informational roles. First, a topical subordinate can take a resumptive anaphoric pronoun ${ }^{14} z h e$ 'this' or na 'that', as in (13) below. A focal subordinate cannot, cf. (15)

$$
\begin{aligned}
& \text { ruguo ni zai tuici, jiu bu heshi le } \\
& \text { if you again decline } j i u \\
& \text { if you refuse again, it won't be accepted }
\end{aligned}
$$

ruguo ni zai tuici, zhe/na jiu bu heshi le if you again decline this/that jiu Neg. adequate F.P. if you refuse again, it won't be accepted

$$
\begin{aligned}
& \text { yaoshi duo lianxi cai tigao chengji } \\
& \text { if much practice cai increase grade } \\
& \text { it's only if you practice a lot that you will have better grades }
\end{aligned}
$$

13 For the use of meta-linguistic shi, see Teng (1974).

14 The presence of a resumptive clitic is symptomatic of topicality (=old information), cf. Cinque $(1990: 63,180)$. 


$$
\begin{array}{lll}
\text { *yaoshi duo lianxi, zhe/na cai tigao chengji } \\
\text { if } \quad \text { much practice this/that cai increase grade }
\end{array}
$$

Second, a conditional clause cannot be clefted, while a causal one can. Morover, as clefting is available when the adjunct precedes the matrix, as in (17), this proves that a causal proposition cannot occupy a functional projection labelled Topic Phrase. By definition, a topic cannot be clefted.

$$
\begin{aligned}
& \text { *shi zhiyou tianqi hen hao, wo cai lai de } \\
& \text { be only weather very good I cai arrive de } \\
& \text { shi yinwei tianqi hen hao wo cai lai de } \\
& \text { be because weather very good I cai come de } \\
& \text { I came only because the weather is good }
\end{aligned}
$$

In passing, let's try to explain the difference between (04) and (05) above. Jiu marks both a logical and an anaphoric relationship between the antecedent/protasis (noted $p$ ) and the consequent/apodosis clause (noted $q$ ). In (04) we are dealing with a question about a conditional. Such types of conditionals are close to what has been called conditional speech act clauses in the literature ${ }^{15}$. Jiu is kept in (05) because what is questioned by the speaker is precisely the relationship between $p$ and $q$, which $j i u$ stands for : it is a conditional question. Moreover in (05) because jiu is in the scope of a modality, it indicates the distance that the speaker takes with respect to the utterance of such a relation. The opposition between will and would in the English translations of (04) and (05) tries to render the meaning difference between these two examples.

We now turn to simple sentences containing a quantified object.

\subsection{Simple sentences}

In simple sentences containing a quantified object both jiu and cai function as restrictive operators, which alternate with $z h i$ 'only', cf. $(20)^{16}$. (19) is the interrogative counterpart of (18), which does not contain any restrictive operator.

$$
\text { ta he-le yi bei jiu }
$$

he drink-Suf. one $\mathrm{Cl}$. alcohol

he drank a glass of wine

$$
\begin{aligned}
& \text { ta you mei you he yi bei jiu? } \\
& \text { he have-Neg-have drink one } \mathrm{Cl} \text {. alcohol } \\
& \text { has he drunk a glass of wine? }
\end{aligned}
$$

$$
\begin{aligned}
& \text { ta jiu/cai/zhi he-le yi bei jiu } \\
& \text { he only/only/only drink-Suf. one } \mathrm{Cl} \text {. alcohol } \\
& \text { he only drank a glass of wine }
\end{aligned}
$$

\footnotetext{
15 See Eifring (1995).

The formal approach used by Jayez and Rossari (1999) to account for the connectors dans ce cas and donc in French seems very promising. Intuitively, it can be extended to $j i u$ whose meaning is closer to dans ce cas than to donc.

16 For the meaning differences between these restrictors, see Paris (1981).
} 
If the informational role carried by the predicative phrase of (18) and (20) were identical, we would expect that from the interrogative example (19) one would form (21), because both examples are built on the same pattern. But (21) is ill-formed. As was the case above for focal subordinate clauses - see (11) - only a shi bu shi question is allowed. What is questioned is not the (lexical) verb he 'drink', but the quantity represented by the numeral expression yi bei 'one glass', cf. (22).

$$
\begin{aligned}
& \text { *ta jiu/cai/zhi you mei you he yi bei jiu? } \\
& \text { he only/only/only have-Neg-have drink one Cl. alcohol } \\
& \text { ta shi bu shi jiu/cai/zhi he-le yi bei jiu? } \\
& \text { he be-Neg-be only/only/only drink-Suf. one Cl. alcohol } \\
& \text { has he only drunk one glass of wine? }
\end{aligned}
$$

Examples (23)-(26) below are very revealing. They are simple sentences which contain the same markers as necessary conditionals - zhiyou and cai in (06) or (11) above - and pattern exactly like them. An object which normally occupies the postverbal position as in (18)(20) and (22) must appear preverbally or sentence initially when it is focussed by zhiyou 'only', cf. (23). In this case, it has wide scope.

$$
\begin{aligned}
& \text { zhiyou bai jiu ta (cai) bu he } \\
& \text { only white wine he (cai) Neg. drink } \\
& \text { it's only white wine that he does not drink }
\end{aligned}
$$

As the object is the carrier of new information, it is this very constituent - and only it which is in the scope of the question. Hence the verb cannot display such a property: this is why (24)-(25) are ill-formed.

$$
\begin{aligned}
& \text { *zhiyou bai jiu ta (cai) he bu he? } \\
& \text { only white wine he (cai) drink-Neg.-drink }
\end{aligned}
$$

*zhiyou bai jiu ta shi bu shi (cai) bu he? only white wine he be-Neg-be (cai) Neg. drink

$$
\begin{aligned}
& \text { shi bu shi zhiyou bai jiu ta (cai) bu he? } \\
& \text { be-Neg-be only white wine he (cai) Neg. drink } \\
& \text { is it only white wine that he does not drink? }
\end{aligned}
$$

What (26) above illustrates is that (i) cai has inverse scope: it does not precede the element it modifies and that (ii) surface word order cannot be equated with informational order. The quantified phrase zhiyou bai jiu 'only white wine' does appear in sentence initial position, but it does not display topical properties. Quite to the contrary, the place of shi bu shi shows that it is in the scope of the question, hence it bears the new information.

In the following I will show how the pairing of question/answer in simple sentences tells us directly where the new information is located in a Chinese sentence. 


\section{Constiuent questions and word order}

As is very well-known, in Chinese, bare NPs which function as time adverbials can occupy different pre-verbal positions. For example, in (01)-(03) zuotian 'yesterday' occupies the sentence initial, the post-manner adverbial and the post-subject positions, respectively.

$$
\begin{aligned}
& \text { zuotian ni guyi da-le ta } \\
& \text { yesterday you on purpose beat-Suf. he } \\
& \text { yesterday you beat him on purpose }
\end{aligned}
$$

$$
\begin{aligned}
& \text { ni guyi zuotian da-le ta } \\
& \text { you on purpose yesterday beat-Suf. he } \\
& \text { you beat him on purpose yesterday }
\end{aligned}
$$

$$
\begin{aligned}
& \text { ni zuotian guyi da-le ta } \\
& \text { you yesterday on purpose beat-Suf. he } \\
& \text { yesterday you beat him on purpose }
\end{aligned}
$$

But corresponding to these three orders, only one question, i.e. (06), is well formed. (04) and (05) are not acceptable.

$$
\begin{aligned}
& \text { *shenme shihou ni guyi you on purpose beat-Suf. he } \\
& \begin{array}{l}
\text { when? } \\
\text { *ni guyi shenme shihou da-le ta? } \\
\text { you on purpose when? beat-Suf. he }
\end{array}
\end{aligned}
$$

What (06) shows is where the base position for time constituents lies. The other orders show different informational and scopal properties. When it is in sentence initial/topical position, a constituent cannot be questioned, as evidenced by (04) (and (10) below). As is expected cross-linguistically, the scope of time constituents is wider than that of manner adverbials. (05) is ill-formed because guyi 'on purpose' has wider scope than shenme shihou 'when?'.

Locative phrases show even more clearly than time phrases how scopal and syntactical properties $^{17}$ interrelate. When it is in sentence initial/topical position, a locative phrase cannnot be questioned, as is evidenced by the constrast in grammaticality between (09) and (10). The unacceptability of (10) is parallel to that of (04). (09)-(10) are the interrogative counterparts of (07)-(08), which are individual-level/generic predications.

$$
\begin{aligned}
& \text { ta zai gongyuan-li pao- } \varnothing \text { bu } \\
& \text { he at park-in run- } \varnothing \text { step } \\
& \text { he runs in the park }
\end{aligned}
$$

17 Following Maienborn (1999), the locative phrase (LocP) in (07) can be labelled 'situation-external modifier', and the Loc P in (08) 'frame-setting modifier'. 
(08)

zai gongyuan-li ta pao- $\varnothing$ bu

at park-in he run- $\varnothing$ step

in the park he runs

(09) ta zai bu zai gongyuan-li pao- $\varnothing$ bu?

he at-Neg-at park-in run- $\varnothing$ step does he run the park?

(10) *zai bu zai gongyuan-li ta pao bu? at-Neg-at park-in he run- $\varnothing$ step

The answers to (09) are (11) or (12).

$$
\begin{aligned}
& \text { shi, zai gongyuan-li pao bu } \\
& \text { be at park-in run- } \varnothing \text { step } \\
& \text { yes, he runs in the park } \\
& \text { (shi, ta) zai } \\
& \text { (be he) at } \\
& \text { yes, he does }
\end{aligned}
$$

(13) below is the interrogative stage-level/episodic counterpart of (07) above: the verb is suffixed either by $-l e$ or by $-g u o$, and (14) is its interrogative counterpart. The contrast between (15) and (16) shows that the locative in (14) cannot stand for new information, because (16) cannot stand as an answer to (14). What constitutes the domain of new information is the time reference, as evidenced by (15), where the answer simply consists in a suffixed verb.

$$
\begin{aligned}
& \text { ta zai gongyuan-li pao-le/-guo bu } \\
& \text { he at park-in run-Suf. } \\
& \text { he has run in the park }
\end{aligned}
$$

he at park-in run-Suf. step Inter.

has he (ever) run in the park?

$$
\begin{aligned}
& \text { pao-le/guo } \\
& \text { run-Suf. } \\
& \text { yes, he has }
\end{aligned}
$$

$$
\begin{aligned}
& \text { *zai (gongyuan-li ) } \\
& \text { at (park-in) }
\end{aligned}
$$

From the pair $(07) /(13)$ we can conclude that in the absence of specific information about time reference, locative reference takes over as a candidate for new information. In the presence of time/aspectual reference, locative reference cannot take over. This is why (16) cannot constitute an answer to (13). The relative informational weight of time and locative constituents is illustrated in the contrast between (17) and (18). Time phrases must precede locative phrases. Such an order is a direct reflection of their relative scope. 


$$
\begin{aligned}
& \text { ni xianzai zai zhe-li xiuxi } \\
& \text { you now at here rest } \\
& \text { now you can rest here } \\
& \text { *ni zai zhe-li xianzai xiuxi } \\
& \text { you at here now rest }
\end{aligned}
$$

The difference between (07) and (13), which apparently simply lies in the absence vs. presence of an aspectual suffix, is more complex than it seems. I have tried to show that the locative constituent zai gongyuan $l i$ 'in the park' plays a different informational role $^{18}$ in both examples. The iconic and the (isomorphic) scope principles that I have presented above in part I cannot account for such a difference.

\section{Conclusion}

In this paper I have tried to show that the interrogative surface word order of sentences, whether they are simple or complex sentences, is a direct reflection of where the new information lies in Chinese. I have mentioned three types of interrogation: interrogative words, verb-negation-verb questioning and shi-negation-shi questioning.

A difference between 'neutral' sentences and sentences containing a presupposition has stood out. In the presence of a presupposition, such as is the case with simple sentences containing focussing/restrictive adverbs or with complex sentences indicating a necessary condition, I have tried to show that the locus of new information does not stand where either formal or functional linguists have predicted it to appear. First, the fact that the question is asked with $s h i$-bu-shi tells us that the sentence contains a presupposition. Second, the position of shi-bu-shi tells us on which constituent(s) it is associated. I have tried to establish a relationship between the surface word order of certain constituents, their scopal and informational properties.

Isomorphism in Chinese - whether it be a direct relation between world events and linguistic word order, or between word order and informational structure or between word order and the interpretation of scope - may not be as transparent as thought of until now.

18 The relationship between the interpretation of locative phrases and aspectual markers is transparent in Korean. Korean has an indefinite aspectual marker un il $i$ ss (noted $\operatorname{Exp}_{1}$ ) and a definite aspectual marker ess-ess (noted $\mathrm{Exp}_{2}$ ). In a yes/no question containing a locative phrase, the locative phrase is interpreted as the focus of the question only when the event is presupposed to have happened, i.e. when the experiental marker is definite. When the experiental marker is indefinite, the question is neutral. See Kim (1998) whose examples I have borrowed. (i) and (ii) correspond to Kim's (57a) and (ii) to a variant of (58), respectively.

(i) ne New York ey ka-n il i iss-ni? you New York to go $\operatorname{Exp}_{1}$ Inter.

have you been to New York? (neutral question)

(ii) ne (cinan cwu) New York ey ka-ss-ess-ni?

you (last week) New York to go $\operatorname{Exp}_{2}$ Inter.

did you go to New York [or some place else](last week)? 


\section{Bibliography}

AOUN, Joseph \& A. LI (1989) Scope and constituency. Linguistic Inquiry 20, 141-172.

BURING, Daniel (1997) The great scope inversion conspiracy. Linguistics and Philosophy 20.2. 175-194.

De SWARTE, Henriette (1998) Licensing negative polarity items under inverse scope. Lingua

CINQUE, Guglielmo (1990) Types of $A^{\prime}$ dependencies. Cambridge : M.I.T. Press.

EIFRING, Halvor (1995) Clause combination in Chinese. Leiden : Brill.

ERNST, Thomas (1994) Conditions on Chinese A-Not-A questions. Journal of East Asian Linguistics 3.3. 241-264.

GASDE, Horst-Dieter \& W. PAUL (1996) Functional categories, topic prominence, and complex sentences in Mandarin Chinese. Linguistics 34. 263-294.

GASDE, Horst-Dieter (1998) Topics, foci and sentence structure in Mandarin Chinese. Sprachtypologie und Universalienforschung 1. 43-94.

HUANG, Shuan-fan (1981) On the scope phenomena of Chinese quantifiers. Journal of Chinese Linguistics 9. 226-243.

HUANG, James (1982) Logical relations in Chinese and the theory of grammar. Ph. D. dissertation, MIT.

JAYEZ, Jacques \& C. ROSSARI (1999) When anaphoric and logical discourse makers meet accomodation. Talk delivered at CSSP [Conférence de Syntaxe et de Sémantique de Paris], Paris 7 University.

KIM, Nam-kil (1998) On experiential sentences. Studies in language 22.1. 161-204.

KUNO, Susumu \& K. TAKAMI \& Y. WU (1999) Quantifier scope in English, Chinese, and Japanese. Language 75.1.63-111.

LE QUERLER, Nicole (1993) Subordination, thématisation, rhématisation: l' exemple de la cause. In C. Muller, D. Roulland (eds): Subordinations 6. (Travaux Linguistiques du CERLICO). Rennes: Presses Universitaires de Rennes.

LEE, Thomas \& V. YIP \& C. WANG (1999) Rethinking isomorphism as a scope principle for Chinese and English. In Sun, Chaofen (ed), Proceedings of the 10th North American Chinese Linguistics Conference

MAIENBORN, Claudia (1999) Setting the scene for topic/comment. In this volume.

PARIS, Marie-Claude (1981) Problèmes de syntaxe et de sémantique en linguistique chinoise. Mémoires de l'Institut des Hautes Etudes Chinoises XX. Paris : Collège de France.

PARIS, Marie-Claude (1983) Marqueurs et corrélateurs hypothétiques en mandarin. Verbum VI. 3. 327 342.

PARIS, Marie-Claude \& I. TAMBA (1984) Quelques aspects de la concession en chinois et en japonais. Actes du Colloque sur l'expression de la concession, Paris IV. Linguistica Palatina Colloquia I.163179.

TAI, J. H.-Y. (1989) Toward a cognition-based functional grammar of Chinese. Functionalism and Chinese Grammar. In J. Tai \& F. Hsueh eds., Seton Hall, Monograph Series, Journal of the Chinese Language Teachers' Association, 187-226.

TENG, Shou-hsin (1974) Negation in Chinese. Journal of Chinese Linguistics 2. 125-140.

TSAI, Mei-chih (1995a) Les causales et les conditionnelles en chinois: deux projections différentes? Dixièmes journées de linguistique d'Asie Orientale, May 16-17, 1995, Paris, EHESS-CRLAO.

TSAI, Mei-chih (1995b) La modification adverbiale et l'ordre des mots en chinois. Ph. D. Dissertation, Paris 7 University.

TSAO, F.-F. (1990) Sentence and clause structure in Chinese: a functional perspective. Taipei : Student Book Co. 